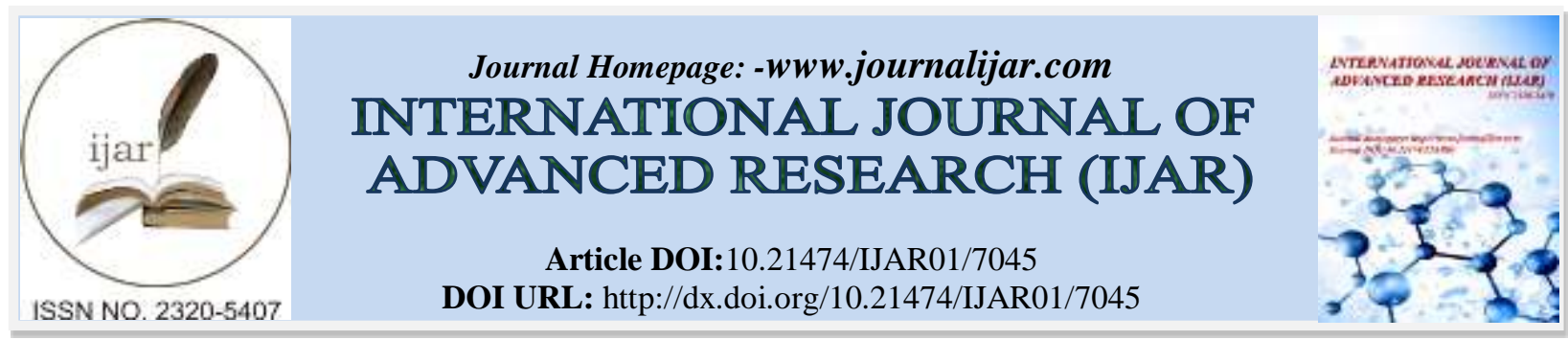

RESEARCH ARTICLE

\title{
CORTICOSTEROID PHOBIA AMONG PARENTS OF ASTHMATIC CHILDREN AND ITS IMPACT ON ASTHMA MANAGEMENT IN HAIL REGION.
}

\section{Hawreyah J Alshamary ${ }^{1}$, Shamma M Alaezaimee ${ }^{1}$, Bayan D Aldokheel ${ }^{1}$, Maram S Alnabri ${ }^{1}$, Saleh A} Alammari ${ }^{1}$ and Nawaf $K$ Almuzaini ${ }^{1}$ and Dr. Somaia Ibrahim Bashir ${ }^{2}$.

1. $4^{\text {th }}$ year students at college of medicine, university of Hail.

2. MBBS, MD pediatrics and child health- Associate professor, college of medicine, Hail university, Hail, Saudi Arabia.

\section{Manuscript Info}

Manuscript History

Received: 06 March 2018

Final Accepted: 08 April 2018

Published: May 2018

\section{Abstract}

Asthma is one of the most common chronic diseases of childhood. ICS are the cornerstone of asthma treatment in adults and children.

The aim of the study to detect and estimate the presence of phobia among parents of asthmatic children and to measure the impact of corticosteroid phobia on management and control of childhood asthma. 326 parents of asthmatic children were interviewed using structural questionnaire.

The study showed that $84.53 \%$ have phobia due to use corticosteroid and $14.92 \%$ haven't, and most of the parents who have corticosteroid phobia either minimized the prescribed dose of corticosteroid $(49.7 \%)$ or completely stopped it $(22.5 \%)$ which is significantly high when compared to those who have no phobia who minimize the dose of corticosteroid $(23.5 \%)$ and those who completely stopped it (17.6\%).

Conclusion: This study aims to state the presence of phobia towards corticosteroid use in the management of asthma among parents of asthmatic children and its effect on their treatment.

from the results It is clear that there is true fear of using corticosteroid. Multiple sources including medical staff are the main cause of parents' phobia towards corticosteroid use.

The study also showed that there is a significant impact of this phobia on the adherence to prescribed corticosteroid for treatment or control of bronchial asthma, as considerable number of parents stopped or minimized the dose due to their phobia.

Copy Right, IJAR, 2018,. All rights reserved.

\section{Introduction: -}

Asthma is a condition in which your airways narrow and swell and produce extra mucus. This can make breathing difficult and trigger coughing, wheezing and shortness of breath ${ }^{(1)}$.

nestimate released in December 2016, there were 383000 deaths due to asthma in 2015 and arou WHO have 235 Several factors have been known to precipitate asthma symptoms .million people currently suffer from asthma blockers, indoor -ysical exercise, aspirin and other NSAIDs, betaincluding cold air, extreme emotional arousal, ph 
allergens (house dust mites in bedding, carpets and stuffed furniture, pet dander), outdoor allergens (especially pollution molds and pollen), tobacco smoke, chemical irritants in the workplace and air ${ }^{(2)}$.

Asthma is one of the most common chronic disorders in Saudi Arabia as more than 2 million Saudis suffer from asthma $^{(3)}$.

Poor knowledge, fear of the use of new drugs, and the lack of awareness of the importance of disease control are among primary care physicians who care for asthma patients in Saudi Arabi commonaIn addition to these important factors, there are other attributes to the magnitude of disease burdens such as socioeconomic status, number of and income. Consequently, many asthma patients continue to be underdiagnosed, ,siblings, knowledge of caregivers undertreated, and at risk of acute exacerbations resulting in missed work or school, increased use of expensive acute healthcare services, and reduced quality of life ${ }^{(4)}$.

Kabbaa et al. found that only $39 \%$ of primary care physicians met the standards of the national -dy by AlA stu guidelines in management of asthma ${ }^{(5)}$.

low (52\%). Their proficiency in general ysicians wasph all level of awareness among In addition, the over and management was also low. An asthma control survey of ,edge, diagnosis, classification of severityknowl olled, and $64 \%$ werecontr patients showed that only $5 \%$ of the patients were controlled, $31 \%$ were partially uncontrolled $^{(6)}$.

an ion of school children aged between 8 and 16 years was studied usingpopulat otw of asthma in The prevalence 1995 internationally designed protocol in 1986 and $^{(7)}$.

inland desert are as with dry environment) and Jeddah versus) dh versus HailRiya data from Comparison of the of asthma in similar population increased revealed that the prevalence (zan (coastal humid environmentJa 1995 in 1986 to $23 \%$ in significantly from $8 \%{ }^{(8)}$.

moke and tobacco s study also revealed that there was increased exposure to environmental factors such as The which may have contributed ,indoor animals in Saudi houses. -et al. compared the prevalence of physician Bener -cross among Saudi school boys in the industrial city of Yanbu to two non industrial villages in a asthma diagnosed sectional study ${ }^{(9)}$.

a respectively. Hijazi et al. conducted ,\%8 e prevalences in industrial and nonindustrial are as were $13.9 \%$ andTh urban and 424 rural children aged 12 years They attempted to compare the prevalence of allergic 1020 of study with ing in urban and rural areas of the Saudi Arabia and investigate factors associatedsymptoms among those liv found y differencesan ${ }^{(10)}$.

rural The prevalence of allergic symptoms was found to be significantly greater among urban children than the Saudi children-Saudi than non was more among ones and ${ }^{(11)}$.

eye and skin symptoms. more had rtain respiratory symptoms and femalesMales were more susceptible to have ce influence the likelihood of having symptoms ccupation of the father did notand o educational level The ${ }^{(4)}$.

Asthma can be effectively treated and most patients can achieve good control of their asthma. When asthma is under good control, patients can:

Avoid troublesome symptoms during day and night

Need little or no reliever medication

y active livesHave productive, physicall

Have normal or near normal lung function

(ups (exacerbations, or attacks-Avoid serious asthma flare ${ }^{(12)}$.

In contrast, the 2016 Global Initiative for Asthma (GINA) guidelines categorize asthma severity as mild, moderate, or severe. Severity is assessed retrospectively from the level of treatment required to control symptoms and exacerbations, as follows:

Mild asthma: Well controlled with as-needed reliever medication alone or with low-intensity controller treatment such as low-dose inhaled corticosteroids (ICSs), leukotriene receptor antagonists, or chromones. 
Moderate asthma: Well controlled with low-dose ICS/long-acting beta2-agonists (LABA)

Severe asthma: Requires high-dose ICS/LABA to prevent it from becoming uncontrolled, or asthma that remains uncontrolled despite this treatment ${ }^{(13)}$.

The 2016 GINA guidelines include the following stepwise recommendations for medication and symptom control: Step 1: As-needed SABA with no controller; other options are to consider low-dose ICS for patients with exacerbation risks.

Step 2: Regular low-dose ICS plus as-needed SABA; other options are LTRA or theophylline.

Step 3: Low-dose ICS/LABA plus as-needed SABA or ICS/formoterol maintenance and reliever therapy; other options are medium-dose ICS or low-dose ICS/LABA.

Step 4: Low-dose ICS/formoterol maintenance and reliever therapy or medium-dose ICS/LABA as maintenance plus as-needed SABA; add-on tiotropium for patients with history of exacerbations; other options are high-dose ICS/LTRA or slow-release theophylline; refer for expert assessment and advice.

Step 5: Refer for expert investigation and add-on treatment; add-on treatments include tiotropium by mist inhaler for patients with a history of exacerbations, omalizumab for severe allergic asthma, and mepolizumab for severe eosinophilic asthma; other options are that some patients may benefit from low-dose oral corticosteroids but longterm systemic adverse effects occur ${ }^{(14)}$.

\section{Inhaled corticosteroid(ICS):}

Because of their clinical efficacy and anti- inflammatory properties, ICS are the cornerstone of asthma treatment in adults and children. They remain the most effective anti-inflammatory drugs for the treatment of persistent asthma. Since their introduction in the early 1970s, no other equally remain so for the foreseeable future. Treatment with ICS has decreased asthma mortality and morbidity ${ }^{(15)}$.

In addition, treatment with ICS reduces symptoms, improves lung function, reduces the degree of bronchial hyperresponsiveness (BHR) and reduces the number of exacerbations. ICS treatment improves the burden of asthma by decreasing the number of nocturnal awakenings due to respiratory symptoms, by reducing school absence and, especially valuable for children, by helping to enable participation in sports and other social activities ${ }^{(16)}$.

Adherence to therapy and therapy convenience are key to the successful pharmacological management of asthma, particularly in children ${ }^{(17)}$.

The mechanisms of steroid resistance in these individuals are poorly understood but are thought to include abnormalities in glucocorticoid receptor function, corticosteroid pharmacokinetics, or transcription factor protein activity $^{(18)}$.

There is a range of local side effects that includes perioral dermatitis, tongue hypertrophy, oral and oropharyngeal candidiasis, pharyngeal inflammation, laryngeal disorders, cough during inhalation, and a sensation of thirst ${ }^{(19)}$.

Systemic side effects are dose-dependent, and obvious differences exist between ICSs in their ability to cause systemic glucocorticoid activity. Problems include the following: calcium and phosphate metabolism with subsequent risk of osteoporosis; adrenocortical suppression; bruising and skin thinning; posterior subcapsular cataracts; and glaucoma ${ }^{(19)}$.

Systemic corticosteroids have been shown to improve outcome in hospitalized children with acute asthma, including earlier discharge and fewer relapses. Early use of systemic corticosteroid therapy in acute exacerbations of asthma in adults and children, reduces hospital admissions and also prevents relapse in the emergency department setting ${ }^{(20)}$. Oral corticosteroids for children: $0-5$ years.

Few clinical trials have assessed the effectiveness of oral corticosteroids for managing flare-ups of wheezing in preschool children, and there is very little evidence about their effects in children who are not being treated in hospitals or emergency departments. 
Short courses of oral corticosteroids initiated by parents in response to the onset of wheezing symptoms do not appear to reduce the need for hospitalization or treatment in the emergency department for preschool children.

For children age 1-5 years with wheezing due to a respiratory tract virus such as the common cold, a short course of oral prednisolone does not reduce the severity of symptoms.

Oral corticosteroids for children: 6 years and over.

A short course of oral corticosteroid may be helpful in gaining rapid asthma control, with a low risk of additional systemic adverse effects.

Rarely, long-term systemic corticosteroids may be needed for children with severe persistent asthma that is poorly controlled despite high-dose inhaled corticosteroids and long-acting beta2 agonists. However, significant adverse effects may occur due to recurrent or long-term systemic corticosteroids ${ }^{(21)}$.

Phobia denotes an extreme aversion, avoidance and fear. One of the basic tenets of the concept of phobia is the fear is irrational leading to a deliberate avoidance of the item producing it, and the condition leads to gross sociooccupational dysfunction. That the fear is irrational is sometimes even acknowledged by the patient himself but when exposed to it, he cannot help avoiding it ${ }^{(22)}$.

CS fear and CM usage are prevalent. Parents with CS fear were more likely to have children with poorer asthma control and have used Chinese medicine. Physicians caring for children with asthma should be aware of parents with CS fear, prepared to address the fear or concerns and offer evidence-based alternative treatment ${ }^{(23)}$.

\section{Research objective: -}

To detect and estimate the presence of phobia among parents of asthmatic children.

To measure the impact of corticosteroid phobia on management and control of childhood asthma.

Research Methodology: -

This is a cross-sectional community and hospital-based study done in the period of two months (January - February 2018.

326 Parents of asthmatic children aged $0-15$ years were included in the study.

\section{Inclusion criteria: -}

Parents of children diagnosed as bronchial asthma patients(GINA).

\section{Exclusion criteria: -}

Children with chronic respiratory illness other than asthma and corticosteroid treatment for other reasons.

We use two forms of a structured questionnaire electronic and papers. It is designed to measure the percentage of the presence of corticosteroid phobia and its effect on asthma management. The questionnaire included some patient's demographic data as well as information for asthma duration, admission to hospital, drugs uses for asthma treatment and questions regarding: corticosteroids fear, causes of fear, sources of fear, and result of fear on treatment.

Upon completing the interview, parents were advised to contact with clinicians for further education and assurance about importance and safety of corticosteroid in asthma treatment. Implied consent was obtained from all parents.

Data analysis:-

Data will be analyzed by the computer using SPSS VERSION 22.

\section{Results:-}

Table 1: -Participants demographics.

\begin{tabular}{|l|l|l|l|l|}
\hline Classification & N & $\%$ & \\
\hline Relative relation & Father & 64 & 19.6 \\
\hline & Mother & 262 & 80.4 \\
\hline & Total & 326 & 100.0 \\
\hline
\end{tabular}




\begin{tabular}{|l|l|l|l|}
\hline Place of residence & Hail & 290 & 89.0 \\
\hline & $\begin{array}{l}\text { Governorates of } \\
\text { Hail }\end{array}$ & 12 & 3.7 \\
\hline & Hail villages & 24 & 7.4 \\
\hline & Total & 326 & 100.0 \\
\hline Level of education & Uneducated & 6 & 1.8 \\
\hline & Elementary & 17 & 5.2 \\
\hline & Intermediate & 25 & 7.7 \\
\hline & Secondary & 57 & 17.5 \\
\hline & $\begin{array}{l}\text { University and } \\
\text { above }\end{array}$ & 221 & 67.8 \\
\hline & Total & 326 & $100 \%$ \\
\hline
\end{tabular}

Relative relation: $80.4 \%$ of the participants are Mothers and $19.6 \%$ fathers.

Place of residence: in the same table we find $89.0 \%$ lives in Hail city, $7.4 \%$ in Hail villages and $3.7 \%$ in Governorates of Hail.

Level of education: Table 1 shows that the Level of education of $67.8 \%$ of the participants is university or above $17.5 \%$ secondary, $7.7 \%$ (intermediate), $5.21 \%$ Elementary and $1.84 \%$ are uneducated.

Table 2: -how many of your children do they have asthma?

\begin{tabular}{|l|l|l|}
\hline & Frequency & Percent \\
\hline One & 239 & 73.3 \\
\hline Two & 60 & 18.4 \\
\hline More than Two & 27 & 8.3 \\
\hline Total & 326 & 100.0 \\
\hline
\end{tabular}

Table 2 shows that $73.3 \%$ of the participants have one asthmatic child, $18.4 \%$ have two children and $8.3 \%$ have more than two children who have asthma.

Table 3: -Age of the children with asthma whom parents are included in the study:

\begin{tabular}{|l|l|l|}
\hline & Frequency & Percent \\
\hline From birth to1Year & 31.0 & $7.83 \%$ \\
\hline$>1$ to 5Years & 126.0 & $31.82 \%$ \\
\hline$>5$ Years & 239.0 & $60.35 \%$ \\
\hline Total & 396.0 & $100.00 \%$ \\
\hline
\end{tabular}

Table 3 shows that the age of $60.35 \%$ of the included children is above 5 years, $31.82 \%$ is

between 1 and 5years while $7.83 \%$ are below one year.

Table 4: -age of the child when he/she has been diagnosed as having bronchial asthma?

\begin{tabular}{|l|l|l|}
\hline Diagnosis & Frequency & Percent \\
\hline Infancy & 164 & $50.31 \%$ \\
\hline Preschool & 105 & $32.21 \%$ \\
\hline School-age & 57 & $17.48 \%$ \\
\hline Total & 326 & $100.0 \%$ \\
\hline
\end{tabular}

Table 4 shows $50.31 \%$ of the patients has been diagnosed with asthma since Infancy, $32.21 \%$ during Preschool age and $17.48 \%$ during school age.

Table 5: -Has your child been hospitalized by an asthma attack?

\begin{tabular}{|l|l|l|}
\hline & Frequency & Percent \\
\hline Yes & 167 & 51.2 \\
\hline No & 159 & 48.8 \\
\hline Total & 326 & 100.0 \\
\hline
\end{tabular}

Table 5 shows $51.2 \%$ of the included patients has been hospitalized by an asthma attack. 


\begin{tabular}{|c|c|c|}
\hline \multicolumn{3}{|c|}{ Table 6:- Number of hospitalization } \\
\hline Number of hospitalizes & Frequency & Percent \\
\hline $1-4$ times & 89 & $54.60 \%$ \\
\hline 5 or more times & 74 & $45.40 \%$ \\
\hline Total & 163 & $100.0 \%$ \\
\hline
\end{tabular}

Table 6 shows that $54.6 \%$ of those who have been hospitalized are hospitalized 1 to 4 times, while $45.4 \%$ are hospitalized 5 times or more.

Table 7: -What medications do the child take at the time of the questionnaire?

\begin{tabular}{|l|l|l|}
\hline Medication & Frequency & Percent \\
\hline Bronchodilator & & \\
& 221 & $67.79 \%$ \\
\hline Cortisone & 69 & $21.17 \%$ \\
\hline Traditional medicines & & \\
\hline Nothing & 13 & $3.99 \%$ \\
\hline Total & 23 & $7.06 \%$ \\
\hline
\end{tabular}

Table 7 shows $67.79 \%$ of patients take bronchodilator, $21.17 \%$ take cortisone, $3.99 \%$ use Traditional medicines and $7.06 \%$ are not using any medication.

Table 8: -Do you know what is cortisone?

\begin{tabular}{|l|l|l|}
\hline & Frequency & Percent \\
\hline Yes & 217 & $66.56 \%$ \\
\hline No & 109 & $33.44 \%$ \\
\hline Total & 326 & 100.0 \\
\hline
\end{tabular}

Table 8 shows $66.56 \%$ of sample know cortisone and $33.44 \%$ don't know cortisone

Table 9:-Did you know that the cortisone is used to treat asthma?

\begin{tabular}{|l|l|l|}
\hline & Frequency & Percent \\
\hline Yes & 238 & $73.01 \%$ \\
\hline No & 88 & $26.99 \%$ \\
\hline Total & 326 & 100.0 \\
\hline
\end{tabular}

Table 9 shows $73.01 \%$ of the included parents know that cortisone is used to treat asthma and $26.99 \%$ don't know.

Table 10: -Has cortisone been prescribed before by a doctor to relieve asthma attacks for your child?

\begin{tabular}{|l|l|l|}
\hline & Frequency & Percent \\
\hline Yes & 220 & $67.48 \%$ \\
\hline No & 106 & $32.52 \%$ \\
\hline Total & 326 & 100.0 \\
\hline
\end{tabular}

Table 10 shows $67.48 \%$ of children Has cortisone been prescribed by a doctor to relieve asthma attacks before and $32.52 \%$ don't have.

Table 11: -Have doctor ever explained usefulness, uses or side effects of cortisone to you?

\begin{tabular}{|l|l|l|}
\hline & Frequency & Percent \\
\hline Yes & 87 & $39.55 \%$ \\
\hline No & 62 & $28.18 \%$ \\
\hline He has clarified insufficiently & 71 & $32.27 \%$ \\
\hline Total & 220 & $100 \%$ \\
\hline
\end{tabular}

Table 11 shows $39.55 \%$ had got sufficiently explanation by the doctor about cortisone $28.18 \%$ hadn't got and $32.27 \%$ had got but insufficiently. 
Table 12:- Do you worry about using cortisone for your child?

\begin{tabular}{|l|l|l|}
\hline \multicolumn{2}{|l|}{} \\
\hline & Frequency & Percent \\
\hline Yes & 183 & $84.53 \%$ \\
\hline No & 37 & $14.92 \%$ \\
\hline
\end{tabular}

Table 12 shows $84.53 \%$ have worry due to use cortisone and $14.92 \%$ haven't

\begin{tabular}{|c|c|c|c|c|c|c|}
\hline & & \multicolumn{4}{|c|}{ Relative relation } & \multirow[t]{3}{*}{ Total } \\
\hline & & \multicolumn{2}{|c|}{ Father } & \multicolumn{2}{|c|}{ Mother } & \\
\hline & & $\mathbf{N}$ & $\%$ & $\mathbf{N}$ & $\%$ & \\
\hline \multirow{2}{*}{$\begin{array}{l}\text { do you worry about using cortisone } \\
\text { for your child }\end{array}$} & Yes & 30 & $75.00 \%$ & 153 & $84.53 \%$ & 183 \\
\hline & No & 10 & $25.00 \%$ & 27 & $14.92 \%$ & 37 \\
\hline \multicolumn{2}{|l|}{ Total } & 40 & $100.0 \%$ & 181 & $100.0 \%$ & 220 \\
\hline
\end{tabular}

Table 13: - What is the cause of worry?

\begin{tabular}{|l|l|l|}
\hline & Frequency & Percent \\
\hline Side effects & 123 & $51.46 \%$ \\
\hline Child habituation & 91 & $38.08 \%$ \\
\hline Not effective & 11 & $4.60 \%$ \\
\hline $\begin{array}{l}\text { Increase the severity of the } \\
\text { disease }\end{array}$ & 14 & $5.86 \%$ \\
\hline Total & 239 & $100.0 \%$ \\
\hline
\end{tabular}

Table 13 shows that the Side effects form $51.46 \%$ of reasons concern, Child habituation $38.08 \%$, Not effective $4.6 \%$ and Increase the severity of the disease $5.86 \%$

Table 14:-What is the source of worry?

\begin{tabular}{|l|l|l|}
\hline & Frequency & Percent \\
\hline Social Media & 84 & $43.52 \%$ \\
\hline $\begin{array}{l}\text { Medical staff (doctor, } \\
\text { nurse, etc.) }\end{array}$ & 33 & $17.10 \%$ \\
\hline Family member & 56 & $29.02 \%$ \\
\hline Others & 20 & $10.36 \%$ \\
\hline Total & 193 & $100 \%$ \\
\hline
\end{tabular}

Table 14 shows that the Social Media form $43.52 \%$ of sources of concern, Family member $29.02 \%$ and a Medical staff in $17.1 \%$ of the included parents.

Table 15: -What is the result of being worried?

\begin{tabular}{|c|c|c|c|c|}
\hline \multicolumn{5}{|c|}{ Do you worry about using cortisone for your child? } \\
\hline & & What is the result of worried? & Frequency & Percent \\
\hline \multirow{3}{*}{$\begin{array}{l}\text { Do you } \\
\text { worry }\end{array}$} & \multirow{3}{*}{ Yes } & Continue the same dosage & 48 & $27.7 \%$ \\
\hline & & Minimize the dose & 86 & $49.7 \%$ \\
\hline & & \multirow[t]{2}{*}{ Cut the medicine permanently } & \multirow[t]{2}{*}{39} & \multirow[t]{2}{*}{$22.5 \%$} \\
\hline \multirow[t]{2}{*}{ about } & & & & \\
\hline & & \multirow[t]{2}{*}{ Total } & \multirow[t]{2}{*}{173} & \multirow[t]{2}{*}{$100.0 \%$} \\
\hline \multirow[t]{2}{*}{ using } & & & & \\
\hline & & \multirow[t]{2}{*}{ Continue the same dosage } & \multirow[t]{2}{*}{10} & \multirow[t]{2}{*}{$58.8 \%$} \\
\hline \multirow[t]{2}{*}{ cortisone } & & & & \\
\hline & & \multirow[t]{2}{*}{ Minimize the dose } & \multirow[t]{2}{*}{4} & \multirow[t]{2}{*}{$23.5 \%$} \\
\hline \multirow{3}{*}{$\begin{array}{l}\text { for } \\
\text { child? }\end{array}$} & \multirow[t]{3}{*}{ No } & & & \\
\hline & & Cut the medicine permanently & 3 & $17.6 \%$ \\
\hline & & Total & 17 & $100.0 \%$ \\
\hline
\end{tabular}




\section{Discussion:-}

The aim of this study is to estimate the presence of corticosteroid phobia among parents of children (age $0-15$ years) who suffer from bronchial asthma. The study included 326 parents (80.4\% mothers and $19.6 \%$ fathers), the majority of them are from Hail city (89\%) others are from Governorates of Hail or Hail villages. Most of the parents are highly educated up to university or above $(67.8 \%)$, and only $(1.8 \%)$ of the parents are uneducated, comparing to other study done in Egypt which includes 100 parents only, 65/35 to Male/Female with educational levels ranging from Illiterate (35\%) Primary school (48\%) and High school (17\%). They included children with bronchial asthma whose age between $6-15$ years ${ }^{(24)}$.

$73.3 \%$ of the parents included in the study have only one child with bronchial asthma, while the rest (26.7\%) have more than one affected child.

Bronchial asthma diagnosed during infancy in 7.83\% of the included children, $31.82 \%$ for the children between $1-5$ years, and $60.35 \%$ for the children above 5 years, which also mean that $50.31 \%$ of the patients are infants, $32.21 \%$ at preschool age, $17.48 \%$ are at school age.

The percentage of asthmatic children who have been hospitalized by an asthma attack among the included patients is $51.2 \%, 54.6 \%$ of them have been hospitalized less than 5 times, while $45.4 \%$ have more frequent hospitalization with bronchial asthma attack 5 times or more. On compare with Tracy study the 545 parents of eligible cases, 508 (93\%) completed interviews (133 had hospitalization and 375 had ED visits) ${ }^{(25)}$.

At the time of the study $67.79 \%$ of the included children are on inhaled bronchodilator (Ventolin), $21.17 \%$ are on inhaled corticosteroid and the rest are either on no treatment or they use traditional medications to treat their bronchial asthma. These findings are in disagreement with study done in Egypt who identified Oral steroids were considered by interviewed parents as the most frequent used drug (23\%) in contrary with 7\% ICS, followed by bronchodilators $(16 \%)$. Whereas $25 \%$ of interviewed parents did not know any type of medicines ${ }^{(24)}$.

(66.56\%) know what cortisone is and 33.44\%don't know. Mostly (73.01\%) they are oriented about the role of cortisone in treatment of asthma This is similar to the result in study done in Egypt which showed that orientation of the interviewed parents about the role of steroids in asthma was obvious in $71 \%{ }^{(24)}$.

$26.99 \%$ doesn't oriented about the role of cortisone in treatment of asthma. Cortisone had been prescribed for more than two thirds of the included children (67.48\%) and whom not $(32.52 \%), 39.5 \%$ got full explanation about cortisone's use and side effect and $28.18 \%$ didn't get any knowledge from their physicians and $32.2 \%$ haven't been educated sufficiently. This is similar to the result in study done in Egypt which showed that orientation of the interviewed parents about the role of steroids in asthma was obvious in $71 \%{ }^{(24)}$.

The majority of the included parents -fathers and mothers- who have asthmatic children for whom cortisone is prescribed are worried about using it for their children (84.53\%). That means they have phobia towards using corticosteroid for the treatment or control of their children bronchial asthma.

Most of them worry about the related side effects $(51.46 \%)$ or child habituation, that it will be difficult to wean the child from it (38.08\%), others think that it is not effective or it might increase the severity of the disease. These findings are somewhat similar to what found by a study done in Egypt in which fear of steroid side effects was the strongest theme to emerge (53\%); followed by addiction (9\%), weight gain (6\%) and growth retardation (1\%) also difficulties for ICS use that were mentioned by our participants $(46 \%)^{(24)}$.

Also, Boulet ${ }^{(26)}$ reported that fears and misconceptions about inhaled corticosteroids are quite frequent among the asthmatic population, the two most common being about untoward side effects and a reduction in efficacy with time. The study showed that the main source of worry and concern among the included parents is the social media $(43.52 \%)$, family members or relatives $(29.02 \%)$ and medical staff including doctors $(17.10 \%)$.

This indicates that corticosteroid phobia is significantly present among the general population and also among medical staff.

The study showed that most of the parents who have corticosteroid phobia either minimized the prescribed dose of corticosteroid $(49.7 \% \%)$ or completely stopped it $(22.5 \%)$ total of $84.53 \%$, which is significantly high when 
compared to those who have no phobia towards corticosteroid use in bronchial asthma $23.5 \%$ minimized the prescribed dose of corticosteroid and $17.6 \%$ completely stopped it (total 14.92\%).

This means that the phobia towards corticosteroid significantly affecting the management of children with bronchial asthma and might be reflected on the control of their disease as adherence to medications is one of the important factors that affect childhood bronchial asthma control.

\section{Conclusion:-}

This study aims to state the presence of phobia towards corticosteroid use in the management of asthma among parents of asthmatic children and its effect on their treatment.

from the results It is clear that there is true fear of using corticosteroid. Multiple sources including medical staff are the main cause of parents' phobia towards corticosteroid use.

The study also showed that there is a significant impact of this phobia on the adherence to prescribed corticosteroid for treatment or control of bronchial asthma, as considerable number of parents stopped or minimized the dose due to their phobia.

\section{Recommendations:-}

We recommend firstly to increase health care providers' awareness about delivering effective information to the parents of children with bronchial asthma and to increase the parent's knowledge about treatment plan in their routine sessions.

\section{Acknowledgement:-}

We would like to thank Dr. ZamelAlshamamri, Consultant Pediatrician in King Khalid Hospital, Hail, Saudi Arabia who provided us with the idea and who insight and expertise that greatly assisted the research.

\section{References:-}

1. https://www.mayoclinic.org/diseases-conditions/asthma/symptoms-causes/syc-20369653

2. http://www.who.int/mediacentre/factsheets/fs307/en/

3. Al Moamary MS, Alhaider SA, Al-Hajjaj MS, Al-Ghobain MO, Idrees MM, Zeitouni MO et al. (2012): The Saudi initiative for asthma 2012 update: Guidelines for the diagnosis and management of asthma in adults and children. Ann. Thorac. Med., 7:175-204.

4. Mohamed S. Al-Moamary, Sami A. Alhaider,1 Majdy M. Idrees,2 Mohammed O. Al Ghobain,Mohammed O. Zeitouni,3 Adel S. Al-Harbi,4 Abdullah A. Yousef,5 Hussain Al-Matar,6 Hassan S. Alorainy,7and Mohamed S. Al-Hajjaj8 The Saudi Initiative for Asthma - 2016 update: Guidelines for the diagnosis and management of asthma in adults and children Ann. Thorac. Med., 2016 Jan-Mar; 11(1): 3-42

5. Al-Kabbaa AF, Al-Shamrani KM, Salih MA. Does the management of bronchial asthma by family physicians meet standards of the national protocol? J Family Community Med. 2002;9:21-5. [PMC free article] [PubMed]

6. Al-Jahdali HH, Al-Hajjaj MS, Alanezi MO, Zeitoni MO, Al-Tasan TH. Asthma control assessment using asthma control test among patients attending 5 tertiary care hospitals in Saudi Arabia. Saudi Med J. 2008;29:714-7. [PubMed]

7. al Frayh AR. Asthma patterns in Saudi Arabian children. J R Soc Health. 1990;110:98-100.[PubMed]

8. al Frayh AR, al Nahdi M, Bener AR, Jawadi TQ. Epidemiology of asthma and allergic rhinitis in two coastal regions of Saudi Arabia. Allerg Immunol (Paris) 1989;21:389-93.[PubMed]

9. Bener A, al-Jawadi TQ, Ozkaragoz F, Anderson JA. Prevalence of asthma and wheeze in two different climatic areas of Saudi Arabia. Indian J Chest Dis Allied Sci. 1993;35:9-15.[PubMed]

10. Hijazi N, Abalkhail B, Seaton A. Asthma and respiratory symptoms in urban and rural Saudi Arabia. Eur Respir J. 1998;12:41-4. [PubMed]

11. Alshehri MA, Abolfotouh MA, Sadeg A, Al Najjar YM, Asindi AA, Al Harthi AM, et al. Screening for asthma and associated risk factors among urban school boys in Abha city. Saudi Med J. 2000;21:1048-53. [PubMed]

12. Global strategy for asthma management and prevention (2015 update). Global Initiative for Asthma. http://www.ginasthma.org/documents/4. Accessed April 27, 2015.

13. Asthma Guidelines Classification Guidelines $\quad$ Updated: $\quad$ Nov $\quad 19, \quad 2017$ https://emedicine.medscape.com/article/296301-guidelines\#g2 
14. Asthma Guidelines Classification Guidelines $\quad$ Updated: $\quad$ Nov $19, \quad 2017$ https://emedicine.medscape.com/article/296301-guidelines\#g3

15. Suisa S, Ernst P. Inhaled corticosteroids: impact on asthma morbidity and mortality. J Allergy Clin Immunol. 2001;107:937-944. doi: 10.1067/mai.2001.115653. [PubMed][Cross Ref]

16. Wim M. C. van Aalderen and Aline B. Sprikkelman Inhaled corticosteroids in childhood asthma: the story continues Eur J Pediatr. 2011 Jun; 170(6): 709-718.

17. Soroka Medical Center, Ben-Gurion University, Beer Sheva, Israel,Sympictor : controlling asthma in children,respiratory medicine,vol.96(2002).S23-S28-http://www.resmedjournal.com/article/S0954$6111(02) 80056-7 / \mathrm{pdf}$

18. G W Chalmers, et al. Influence of cigarette smoking on inhaled corticosteroid treatment in mild asthma. Thorax.2002;57:226-230

19. Nicholas J. Roland, et al. The Local Side Effects of Inhaled Corticosteroids. Chestnet .2004. ; 126: 213-219

20. van Asperen PP, Mellis CM, Sly PD, Robertson C. The role of corticosteroids in the management of childhood asthma. The Thoracic Society of Australia and New Zealand, 2010. Available from: http://www.thoracic.org.au/clinical-documents/area?command=record\&id=14

21. Guide to systemic corticosteroids http://www.asthmahandbook.org.au/resources/medicines-guide/systemiccorticosteroids

22. Ghosh A, Sengupta S, Coondoo A, Jana AK. Topical Corticosteroid Addiction and Phobia. Indian Journal of Dermatology. 2014;59(5):465-468.

23. Ip KI, Hon KL, Tsang KYC, Leung TNH. Steroid phobia, Chinese medicine and asthma control. Clin Respir J. 2018 Apr;12(4):1559-1564.

24. Magdy M Zedan, Mohammed Ezz El Regal, Engy A Osman, and Ashraf E Fouda, Steroid Phobia among Parents of Asthmatic Children: Myths and Truth Iran J Allergy Asthma ImmunolSeptember 2010; 9(3): 163168.

25. Lieu TA ${ }^{1}$, Quesenberry CP Jr, Capra AM, Sorel ME, Martin KE, Mendoza GR.Outpatient management practices associated with reduced risk of pediatric asthma hospitalization and emergency department visit PediatricsSeptember 1997, VOLUME 100 / ISSUE 3From the American Academy of Pediatrics.

26. Louis-philippeBoulet, perception of the role and potential side effect of inhaled corticosteroids among asthmatic patients , chest journal, march 1998 volume 113 issue 3 pages 587-592 